\title{
ẢNH HƯỎNG CỦA MÀU SẮC ÁNH SÁNG TỚI KHẢ NĂNG KHAI THÁC MỰC XÀ (STHENOTEUTHIS OUALANIENSIS LESSON, 1830) BẰNG LƯỚI CHỤP MỰC BỐN TĂNG GÔNG
}

\author{
Nguyễn Văn Hải \\ Viện Nghiên cứu Hải sản-Bộ Nông nghiệp và Phát triển Nông thôn Việt Nam \\ E-mail: nvhairimf@gmail.com
}

Ngày nhận bài: 18-12-2013

\begin{abstract}
TÓM TĂT: Năm 2011, 2 chuyến điều tra vùng biển xa bờ miền Trung đã được thưc hiện với 170 mẻ luói chụp mục sử dụng màu sắc ánh sáng đèn ngầm. Ba loại màu sắc ánh sáng đèn ngầm đã được sủ dụng là màu vàng - xanh - trắng. Trung bình mỗi đêm thục hiện 7 mẻ luơơi chụp, đảm bảo mỗi loại màu sắc ánh sáng phải được thực hiện tối thiểu là 30 mẻ với thời gian cho mỗi mẻ luới là 1 giờ. Kết quả nghiên cứu chỉ ra rằng, năng suất khai thác cao nhất ở ánh sáng trắng và thấp nhất ở ánh sáng màu vàng. Năng suất khai thác có sự khác nhau khi sử dụng ánh sáng trắng và ânh sáng màu vàng, các loại ánh sáng khác không có sự khác nhau đáng có ý nghĩa $(P<0,05)$. Chiều dài khai thác trung bình của mục xà không có sự khác nhau có ý nghĩa giữa các loại màu sắc ánh sáng $(P<0,05)$.
\end{abstract}

Tù khóa: Mực xà, bóng đèn ngầm, bóng đèn màu, luới chụp mưc.

\section{ĐẶT VẤN ĐỀ}

Nghề chụp mực kết hợp ánh sáng đã được đưa vào Việt Nam từ những năm 90 của thế kỷ trước để khai thác các đối tượng hải sản vào ban đêm. Đối tượng khai thác chính của nghề này là mực gần bờ và các loài cá nổi nhỏ có tập tính ăn đêm. Sự phát triển của các phương tiện cũng như các công nghệ khai thác trong những năm gần đây đã giúp cho nghề chụp mực có thể vươn khơi xa và đánh bắt những đối tượng hải sản khác ngoài các đối tượng truyền thống. Trong các đối tượng hải sản nghề lưới chụp mực hướng tới thì mực xà như là một đối tượng có tiềm năng lớn. Chúng chiếm tới $98 \%$ sản lượng của các mẻ lưới chụp mực ở vùng biển xà bờ miền Trung.

Trước đây, việc khai thác mực xà chủ yếu là hình thức câu tay trên thúng. Đây là hình thức khai thác rất nguy hiểm cho ngư dân. Do vậy trong những năm gần đây, việc sử dụng lưới chụp kết hợp ánh sáng để khai thác mực xà đã bắt đầu được quan tâm và phát triển. Ánh sáng được sử dụng trong khai thác hoàn toàn là ánh sáng trắng chiếu trên mặt nước. Việc sử dụng ánh sáng đèn ngầm trong khai thác mực xà nói riêng và trong khai thác hải sản ở nước ta nói chung gần như là chưa có. Bên cạnh đó màu sắc ánh sáng được sử dụng đối với các ngư cụ khai thác thường chỉ là ánh sáng trắng, việc sử dụng các loại màu sắc khác nhau chưa được ngư dân và các nhà khoa học quan tâm.

Năm 2010-2011, đề tài "Nghiên cứu kỹ thuật khai thác mực xà (Sthenoteuthis oualaniensis) đã được Viện Nghiên cứu Hải sản triển khai. Với 170 mẻ lưới đã thực hiện bằng việc sử dụng ánh sáng đèn ngầm với 3 loại màu sắc ánh sáng là vàng - xanh - trắng ở vùng biển miền Trung Việt Nam. Bài viết này sẽ trình bày kết quả so sánh về năng suất khai thác cũng như vê chiều dài đánh bắt mực xà bằng lưới chụp mực sử dụng 3 loại bóng đèn 
màu khác nhau. Kết quả nghiên cứu sẽ cung cấp các cơ sở khoa học cho việc đánh giá hiệu quả của việc sử dụng màu sắc ánh sáng trong khai thác mực xà, đồng thời sẽ giúp các nhà quản lý có thêm thông tin để có thể khuyến cáo tới ngư dân trong việc khai thác mực xà.

\section{VÂT LIỆU VÀ PHƯƠNG PHÁP NGHIÊN CỨU}

\section{Vật liệu nghiên cứu}

Đối tượng nghiên của nghiên cứu là loài mực xà (Sthenoteuthis oualaniensis) thuộc họ mực ống đại dương Ommastrephidae (hình 1). Đây là đối tượng khai thác chính của nghề câu chụp mực xà ở nước ta. Năng suất khai thác và sản lượng của mực xà sẽ được dùng để đánh giá kết quả sử dụng 3 loại ánh sáng đèn ngầm trong nghiên cứu.

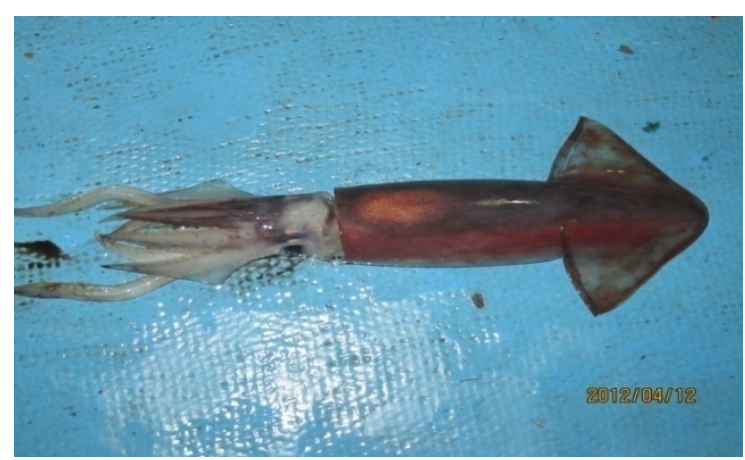

Hình 1. Mực xà
Tổng công suất phát nguồn sáng sử dụng cho mỗi loại màu sắc là $10 \mathrm{kw}$ và đều là các loại bóng đèn chiếu dưới mặt nước. Lưới chụp mực bốn tăng gông với kích thước mắt lưới ở đụt $2 \mathrm{a}=36 \mathrm{~mm}$.

Nguồn số liệu được thu thập qua 2 chuyến điều tra từ tháng 4-7/2011. Vùng biển nghiên cứu là vùng biển xa bờ miền Trung được giới hạn khu vực nghiên cứu từ $12^{0} 30 \mathrm{~N}-15^{\circ} \mathrm{N}$ và từ $110^{\circ} \mathrm{E}-111^{\circ} \mathrm{E}$.

\section{Phương pháp nghiên cứu}

\section{Phưong pháp bố trí thí nghiệm}

Đề tài sử dụng 3 loại màu sắc ánh sáng đèn ngầm (hình 2) cho nghiên cứu, mỗi ngày sẽ sử dụng một màu sắc khác nhau. Ba loại bóng đèn với 3 màu khác nhau (vàng- $\mathrm{V}$, xanh- $\mathrm{X}$, trắngT) lần lượt được bố trí xen kẽ qua các ngày thử nghiệm theo sơ đồ ô vuông la tinh $3 \times 3$, được triển khai theo thứ tự liên tục như sau:

\begin{tabular}{|l|l|l|l|l|l|l|l|l|}
\hline \multicolumn{7}{|c|}{ Bóng đèn chiếu dưới mặt nước } \\
\hline $\mathrm{V}$ & $\mathrm{X}$ & $\mathrm{T}$ & $\mathrm{X}$ & $\mathrm{T}$ & $\mathrm{V}$ & $\mathrm{T}$ & $\mathrm{V}$ & $\mathrm{X}$ \\
\hline
\end{tabular}

Bóng đèn ngầm được bố trí di động hai bên boong tàu, ở độ sâu $5 \mathrm{~m}$ tính từ mặt nước biển. Bóng đèn gom mực được đưa ra ngoài cabin mạn trái của tàu. Bóng đèn gom mực có thể tăng giảm hiệu điện thế để thay đổi cường độ ánh sáng.

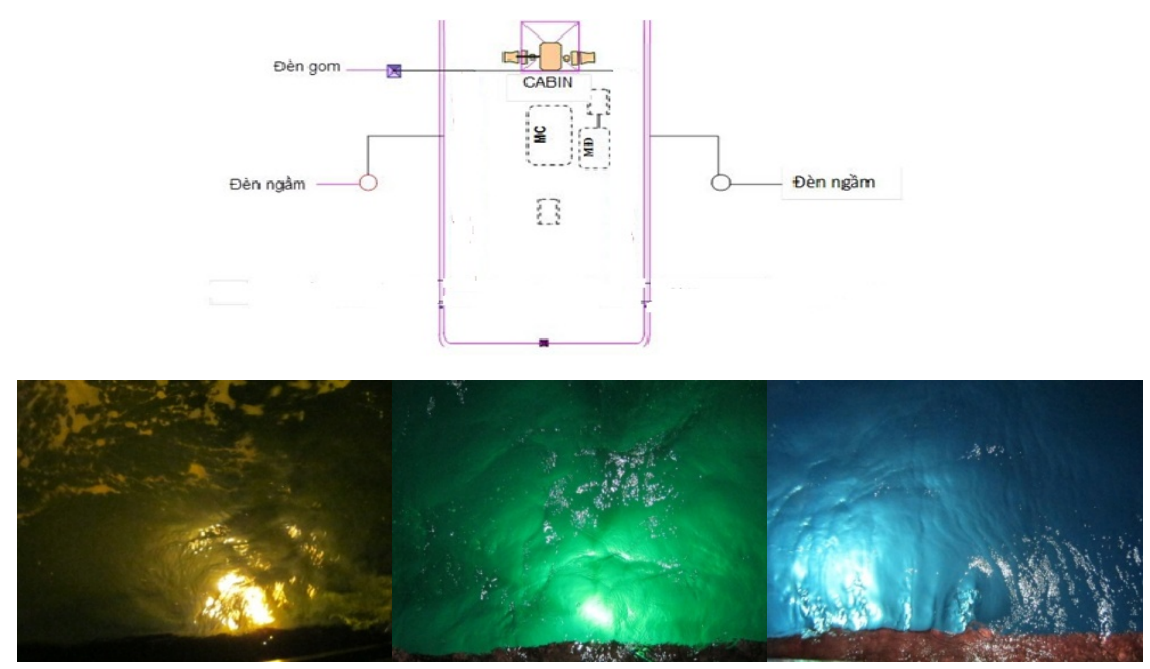

Hình 2. Sơ đồ bố trí bóng đèn hai bên cabin trên tàu và hình ảnh bóng đèn ngầm chiếu dưới mặt nước theo thứ tự vàng - xanh - trắng 


\section{Phương pháp thu thập số liệu}

Số mẻ lưới được thực hiện trong mỗi đêm là 7 mẻ, thời gian qui định thắp đèn cho mỗi mẻ là 1 giờ. Tổng số mẻ lưới tối thiểu phải thực hiện là 30 mẻ/1 loại bóng đèn.

Sau mỗi mẻ lưới, các thông tin về mẻ lưới, kết quả đánh lưới và số liệu sinh học được ghi chép lại đầy đủ trong các biểu chuẩn bị sẵn.

Thông tin về kết quả đánh lưới bao gồm thông tin về sản lượng, thành phần loài trong mẻ lưới. Tên loài được xác định theo tài liệu hướng dẫn phân loại của FAO. Việc cân, đếm số lượng các loài bắt gặp được tiến hành sau khi phân loại các loài.

Số liệu sinh học: Mực xà là đối tượng chính trong nghiên cứu, sau mỗi mẻ lưới sẽ tiển hành lấy mẫu phân tích sinh học mực xà. Các chỉ tiêu phân tích bao gồm: chiều dài bao áo (ML: mantle length); khối lượng toàn bộ $(\mathrm{g})$. Việc thu thập số liệu chiều dài khai thác mực xà có ý nghĩa quan trọng trong so sánh các loại màu sắc ánh sáng. Loại màu sắc ánh sáng nào có khả năng thu hút mực xà lớn tốt hơn cũng sẽ được trình bày khi so sánh chiều dài khai thác mực xà giữa 3 loại màu sắc ánh sáng.

\section{Phuơng pháp chuẩn hóa và phân tích số liệu}

\section{Chuẩn hóa số liệu}

Kết quả nghiên cứu chỉ thực hiện đối với những mẻ lưới đạt yêu cầu. Đó là những mẻ lưới có thời gian chong đèn là 1 giờ và trong quá trình thả-thu lưới không gặp bất kỳ sự cố nào về ngư cu cũng như về thời tiết. Các kết quả nghiên cứu thực nghiệm được nhập vào máy tính, lưu trữ dưới dạng tệp dữ liệu bảng tính (Microsoft excel), sau đó tiến hành hiệu đính số liệu ghi chép thực địa. Số liệu sau khi được hiệu đính sẽ được mã hóa rồi trích xuất sang phẩn mềm thống kê Pasgear II [3] phục vụ cho việc phân tích thông kê chuyên sâu.

\section{Phân tích số liệu}

Sản lượng mẻ lưới: Sản lượng khai thác của lưới chụp mực 4 tăng gông được tính theo mẻ lưới (con/mẻ, $\mathrm{kg} / \mathrm{mẻ})$ cho từng loại bóng đèn chiếu trên và dưới mặt nước theo cổng thức:

$$
\overline{C_{i}}=\frac{1}{n_{i}} \cdot \sum_{j=1}^{n_{i}} C_{i j}
$$

Trong đó, $\bar{C}_{i}$ là sản lượng trung bình mẻ lưới theo số con (con/mẻ) hoặc theo khối lượng $(\mathrm{kg} / \mathrm{mẻ})$ của lưới chụp mực 4 tăng gông sử dụng loại bóng đèn thứ $i, C_{i j}$ là sản lượng mẻ lưới theo số con (con/mẻ) hoặc theo khối lượng $(\mathrm{kg} / \mathrm{mẻ})$ của mẻ lưới thứ $j$ sử dụng loại bóng đèn thứ $i, n_{i}$ là số mẻ lưới hoặc đêm thử nghiệm loại bóng đèn thứ $i$.

Tỷ lệ sản lượng các loài bắt gặp: tỷ lệ (\%) sản lượng của mỗi loài được tính theo công thức dưới đây:

$$
\overline{\% C}_{i k}=\sum_{j=1}^{n_{i}} C_{i k j} \cdot \frac{1}{\sum C_{i k}} \cdot 100 \%
$$

Trong đó, $\overline{\% C}_{i=}$ là tỷ lệ \% sản lượng theo số con hoặc theo khồi lượng của loài thứ $k$ bắt được bằng lưới chụp mực 4 tăng gông sử dụng bóng đèn thứ $i, C_{i k j}$ là sản lượng theo số con hoặc theo khối lượng của loài thứ $k$ bắt được ở mẻ lưới thứ $j$ sử dụng loại bóng đèn thứ $i, C_{i k}$ là sản lượng theo số con hoặc khối lượng của loài thứ $k$ từ loại bóng đèn thứ $i, n_{i}$ là số mẻ lưới thử nghiệm bóng đèn thứ $i$.

Năng suất khai thác được tính theo số $\mathrm{kg} / \mathrm{mẻ}$ và số con/mẻ.

Phân bố chiều dài khai thác mực xà: chiều dài khai thác mực xà được nhóm lại với khoảng chiều dài $1 \mathrm{~cm}$.

\section{Phương pháp đánh giá so sánh kết quả}

Sử dụng phương pháp thống kê Bootstrap [1] để ước tính các khoảng biến động tin cậy cho các giá trị trung bình như sản lượng khai thác mực xà của lưới chụp mực 4 tăng gông ... khi đánh giá, so sánh giữa các loại màu sắc và vị trí đặt bóng đèn chiếu sáng. Phương pháp này được tích hợp trong phần mềm thông kê Pasgear II. Các khoảng giới hạn tin cậy ước tính được so sánh trực quan thông qua phương pháp đồ thị trong phần mềm Pasgear II, hai khoảng giới hạn tin cậy được cho là khác nhau có ý nghĩa thống kê khi chúng không có phần nào chồng lên nhau trên đồ thị.

\section{KẾT QUẢ VÀ THẢO LUẬN}

\section{Năng suất khai thác mụ̣c xà}

Năng suất khai thác của tàu lưới chụp mực được tính theo số $\mathrm{kg} / \mathrm{mẻ}$ lưới. Tùy vào thời gian 
thả lưới lâu hay chậm mà năng suất được qui đổi $\mathrm{ra} \mathrm{kg} / \mathrm{mẻ} / \mathrm{h}$. Trong nghiên cứu này, tất cả các mẻ lưới đều thực hiện trong 1 giờ. Năng suất khai thác trung bình ước tính được trình bày ở bảng 1 .

Bảng 1. Kết quả ước tính năng suất khai thác trung bình theo mẻ lưới của mực xà bắt được bằng lưới chụp mực sử dụng các loại màu sắc ánh sáng khác nhau

\begin{tabular}{|c|c|c|c|c|c|c|c|c|}
\hline \multirow{3}{*}{$\begin{array}{l}\text { Màu } \\
\text { sắc } \\
\text { ánh } \\
\text { sáng }\end{array}$} & \multicolumn{4}{|c|}{ Ước tính năng suất theo số con (con/mẻ) } & \multicolumn{4}{|c|}{ Ước tính năng suất theo khối lượng (kg/mẻ) } \\
\hline & \multirow{2}{*}{$\begin{array}{l}\text { Trung } \\
\text { bình }\end{array}$} & \multicolumn{3}{|c|}{ Giới hạn tin cậy 95\% } & \multirow{2}{*}{$\begin{array}{l}\text { Trung } \\
\text { bình }\end{array}$} & \multicolumn{3}{|c|}{ Giới hạn tin cậy 95\% } \\
\hline & & $\begin{array}{l}\text { Sai số } \\
\text { chuẩn }\end{array}$ & $\begin{array}{c}\text { Giới hạn } \\
\text { dưới }\end{array}$ & $\begin{array}{c}\text { Giới hạn } \\
\text { trên }\end{array}$ & & $\begin{array}{l}\text { Sai số } \\
\text { chuẩn }\end{array}$ & $\begin{array}{c}\text { Giới hạn } \\
\text { dưới }\end{array}$ & $\begin{array}{c}\text { Giới hạn } \\
\text { trên }\end{array}$ \\
\hline V & 114 & 24 & 71 & 164 & 9,4 & 2,5 & 5,7 & 15,3 \\
\hline $\mathrm{X}$ & 173 & 23 & 130 & 222 & 16,5 & 2,4 & 12,2 & 21,5 \\
\hline $\mathrm{T}$ & 204 & 36 & 143 & 283 & 20,9 & 3,8 & 14,4 & 29,3 \\
\hline
\end{tabular}

Trong 3 loại ánh sáng đèn ngầm thử nghiệm, năng suất khai thác mực xà theo mẻ cao nhất ở ánh sáng trắng, trung bình đạt 204 cá thể/mẻ, khối lượng đạt $20,9 \mathrm{~kg} / \mathrm{mẻ}$; tiếp theo là ánh sáng màu xanh, đạt 173 cá thể/mẻ, khối lượng đạt $16,5 \mathrm{~kg} / \mathrm{mẻ}$; thấp nhất là ánh sáng màu vàng, chỉ đạt 114 cá thể/mẻ, khối lượng đạt $9,4 \mathrm{~kg} / \mathrm{mẻ}$. Kết quả phân tích thống kê từng mẻ lưới cho thấy sự dao động lớn về sản lượng, có những mẻ đánh được rất nhiều mực xà song cũng có những mẻ không bắt được cá thể nào. Mẻ lưới đạt sản lượng mực cao nhất là mẻ số 26 của chuyến thứ 2 (ngày 26/5/2011) đạt $117 \mathrm{~kg}$ mực xà, tiếp theo là mẻ số 25 (ngày 26/5/2011) đạt $82 \mathrm{~kg}$, mẻ số 2 (ngày 23/5/2011) đạt $64 \mathrm{~kg}$ và nhiều mẻ đạt sản lượng $30-50 \mathrm{~kg}$. Kết quả thống kê cũng cho thấy, trong tổng số 113 mẻ lưới thực hiện phân tích, có 13 mẻ không có sản lượng mực xà (chiếm tỷ lệ $12 \%$ ), có 39 mẻ có sản lượng nhỏ hơn $10 \mathrm{~kg}$ (chiếm 35\%). Như vậy có thể thấy sản lượng mực xà khai thác bằng bóng đèn ngầm không ổn định, có sự dao động lớn về sản lượng qua từng mẻ; đối với các loại màu sắc ánh sáng khác nhau cũng có sự dao động lớn về sản lượng qua từng mẻ của từng loại ánh sáng.

Năng suất khai thác của một tàu chụp mực phản ánh sản lượng của tàu đó trên một đơn vị tính. Năng suất khai thác không chỉ phụ thuộc vào cường độ chiếu sáng mà còn còn phụ thuộc vào màu sắc, vị trí chiếu sáng, tập tính của loài, điều kiện môi trường, thời điểm thả lưới, kỹ thuật khai thác [2]. Theo kết quả nghiên cứu về sử dụng các loại đèn màu chiếu trên mặt nước trong nghề lưới vây của Đoàn Văn Phụ và Cao Văn Hùng [2] cho biết các loại màu sắc khác nhau cho năng suất khai thác khác nhau với các đối tượng chính. Theo các tác giả này, ánh sáng màu trắng chiếu trên mặt nước có năng suất cao nhất, cao hơn ánh sáng trắng ngầm và cao hơn ánh sáng đỏ, xanh chiếu trên mặt nước.

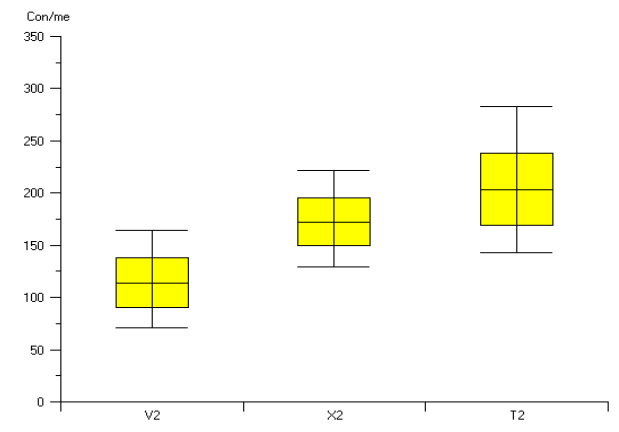

Theo số con

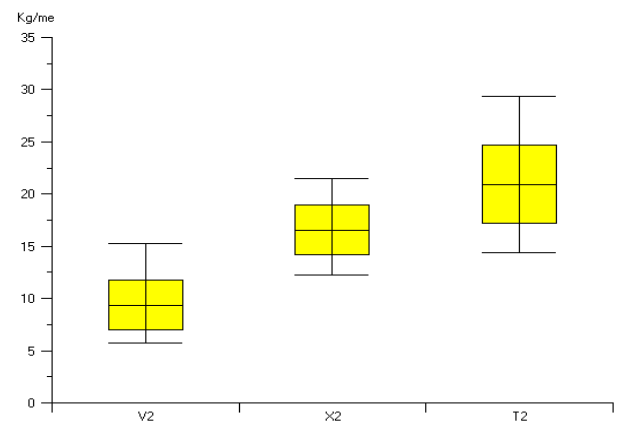

Theo khối lương

Hình 3. So sánh trực quan năng suất khai thác trung bình của mực xà theo mẻ lưới giữa các loại màu sắc ánh sáng 
Kết quả ở hình 3 phân tích năng suất khai thác mực xà ở 3 loại màu sắc ánh sáng theo mẻ lưới. Năng suất khai thác được tính theo $\mathrm{kg} / \mathrm{mẻ}$ và số con/mẻ. Theo đó thì năng suất trung bình mực xà cao nhất khi sử dụng ánh sáng trắng, tiếp theo là ánh sáng màu xanh và cuối cùng là ánh sáng màu vàng. Kết quả so sánh trung bình về năng suất khai thác theo phương pháp bootstrap cho thấy không có sự khác nhau về năng suât khai thác theo mẻ lưới ở 3 loại màu sắc ánh sáng (mức ý nghĩa 95\%). Ở hình 3 chỉ có 1 phần rất nhỏ khoảng tin cậy của ánh sáng màu vàng trùng lên khoảng tin cậy của ánh sáng trắng, giá trị trung bình về năng suất khai thác ở ánh sáng trắng cao hơn rất nhiều so với ánh sáng màu vàng và cao hơn cả ánh sáng màu xanh. Như vậy, giá trị trung bình về năng suất khai thác theo khối lượng ở ánh sáng màu vàng có thể sai khác so với ánh sáng trắng.

\section{Chiều dài khai thác mực xà}

Tổng số 783 cá thể mực xà đã được đo chiều dài hàng loạt. Cá thể nhỏ nhất bắt gặp có chiều dài bao áo là $8,5 \mathrm{~cm}$, và lớn nhất có chiều dài bao áo là $27 \mathrm{~cm}$.

Bảng 2 thể hiện chiều dài khai thác mực xà ở 3 loại màu sắc ánh sáng đèn ngầm. Mực xà bắt được có chiều dài dao động từ $8-27 \mathrm{~cm}$, trung bình $13,6 \mathrm{~cm} /$ cá thể; trong đó, mực xà bắt gặp ở bóng đèn ánh sáng vàng, xanh và trắng lần lượt có chiều dài biến động trong các khoảng $9-27 \mathrm{~cm}$ (trung bình 13,2 cm), 8 $24 \mathrm{~cm}$ (trung bình $14,0 \mathrm{~cm}$ ) và $9-25 \mathrm{~cm}$ (trung bình $13,6 \mathrm{~cm})$.

Bảng 2. Chiều dài khai thác mực xà ở các màu sắc ánh sang đèn ngầm

\begin{tabular}{|c|c|c|c|c|}
\hline \multirow{2}{*}{ Chiều dài } & \multicolumn{4}{|c|}{ Màu sắc ánh sáng } \\
\hline & Vàng & Xanh & Trắng & Chung \\
\hline Nhỏ nhất (cm) & 8 & 10 & 9 & 8 \\
\hline Lớn nhất (cm) & 27 & 24 & 25 & 27 \\
\hline Trung bình (cm) & 13,2 & 14,0 & 13,6 & 13,6 \\
\hline Số cá thể (con) & 184 & 273 & 326 & 783 \\
\hline
\end{tabular}

Ta có thể nhận thấy tỷ lệ nhóm chiều dài nhỏ ở ánh sáng màu vàng cao hơn ở bóng đèn màu trắng và bóng đèn màu xanh. Điều này được thể hiện bởi tỷ lệ các nhóm chiều dài nhỏ cao nhất và tỷ lệ các nhóm chiều dài lớn là thấp nhất. Phân tích thống kê cho thấy, tỷ lệ nhóm chiều dài nhỏ hơn $14 \mathrm{~cm}$ bị khai thác khi sử dụng ánh sáng màu vàng chiếm tới $78 \%$, trong khi tỷ lệ này khi sử dụng ánh sáng trắng là $71 \%$ và ở ánh sáng màu xanh là $64 \%$. Ở nhóm chiều dài trên $22 \mathrm{~cm}$, tỷ lệ thấp nhất là ở ánh sáng màu vàng $(1,6 \%)$, tiếp theo là ánh sáng trắng $(3,1 \%)$ và cao nhất là ánh sáng màu xanh $(3,6 \%)$.

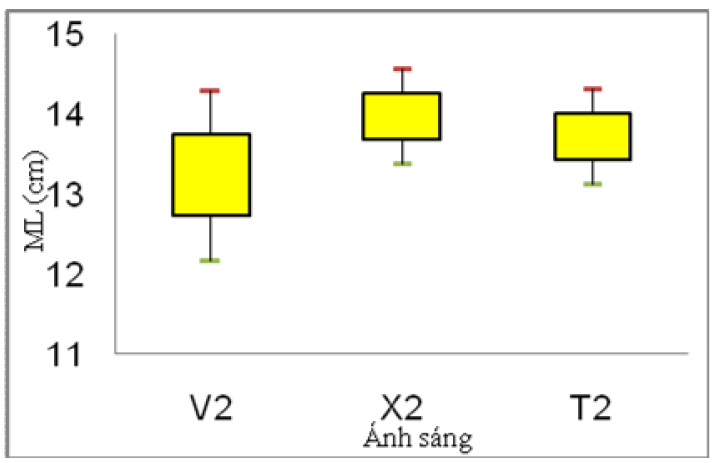

Hình 4. So sánh trực quan chiều dài khai thác mực xà giữa các ánh sáng đèn ngầm.

Kết quả so sánh chiều dài khai thác theo phương pháp Boostrap ở 3 loại màu sắc ánh sáng ngầm được thể hiện ở hình 4 . Phân tích thống kê mô tả cho thấy chiều dài khai thác trung bình của mực xà cao nhất ở khi sử dụng ánh sáng màu xanh. Trên thực tế mặc dù có sự chênh lệch về chiều dài khai thác trung bình của mực xà giữa 3 loại màu sắc ánh sáng, song trong quá trình đánh bắt vẫn bắt gặp rất nhiều cá thể mực xà nhỏ và rất nhiều mực xà lớn ở cả 3 loại màu sắc ánh sáng. Điều này cho thấy cả 3 loại màu sắc ánh sáng đều có khả năng thu hút mực xà lớn và nhỏ.

Chiều dài khai thác phản ánh khả năng bị thu hút bởi ánh sáng và khả năng đánh bắt của ngư cụ. Trong khuôn khổ của đề tài, mắt lưới sử dụng ở đụt lưới có kích thước $2 \mathrm{a}=36 \mathrm{~mm}$. Việc sử dụng ánh sáng trong khai thác mực xà mới được thực hiện bằng ánh sáng màu trắng. Chưa có báo cáo nào nói về tác động của ánh sáng màu tới chiều dài khai thác ở mực xà trong nghề chụp mực. Như vậy có thể thấy, trong 3 loại ánh sáng ngầm sử dụng để khai thác mực xà, không có sự khác nhau về chiều dài khai thác giữa các loại ánh sáng ngầm. Màu sắc được khuyến cáo sử dụng xét trong nghiên cứu là màu xanh do đánh bắt được nhiểu cá thể 
mực xà lớn và có chiều dài khai thác trung bình cao nhất trong 3 loại bóng đèn đã sử dụng.

Tại Việt Nam hiện chưa có nghiên cứu nào về sử dụng màu sắc ánh sáng ngầm trong khai thác mực xà nói riêng và trong nghề chụp mực nói chung. Việc sử dụng 3 loại màu sắc ánh sáng là màu xanh, màu vàng và màu trắng trong nghiên cứu vẫn chưa bao phủ được các loại màu sắc sử dụng trong khai thác hải sản. Vì vậy để có thể khẳng định màu sắc ánh sáng nào là tốt nhất cho nghề chụp mực xà cũng cần có thêm những nghiên cứu nhất định. Qua so sánh trực quan bằng phương pháp bootstrap từ những kết quả nghiên cứu trên có thể thấy rằng ở 3 loại màu sắc đèn ngầm sử dụng trong nghiên cứu cho kết quả về năng suất khai thác không khác nhau. Tuy nhiên, sử dụng ánh sáng trắng coho năng suất trung bình cao nhất, vì thế ánh sáng trắng có ưu thế hơn trong việc khuyến cáo sử dụng trong khai thác mực xà.

\section{KẾT LUẬN}

Sử dụng ánh sáng trắng cho năng suất khai thác trung bình đạt $20,9 \mathrm{~kg} / \mathrm{mẻ}$ cao hơn khi sử dụng ánh sang màu xanh, đạt $16,5 \mathrm{~kg} / \mathrm{mẻ}$ và ánh sáng màu vàng vàng, chỉ đạt $9,4 \mathrm{~kg} / \mathrm{mẻ}$. Có sự khác nhau về năng suất khai thác khi sử dụng ánh sáng trắng và ánh sáng màu vàng để khai thác mực xà. Kích thước khai thác mực xà trung bình ở 3 loại màu sắc ánh sáng xanh, vàng, trắng lần lượt là 13,$98 ; 13,24$ và 13,72 $\mathrm{cm}$. Kích thước khai thác không có sự khác nhau giữa 3 loại màu sắc đèn ngầm.

Xét về khía cạnh năng suất và kích thước khai thác mực xà thì ánh sang trắng có ưu thế nhất trong việc lựa chọn, tiếp theo là ánh sáng màu xanh và không nên sử dụng ánh sáng màu vàng trong khai thác mực xà.

\section{TÀI LIẸU THAM KHẢO}

1. Davision \& Hinkley, 1998. Boostrap Methods and their Application. Cambrige university Press.

2. Đoàn Văn Phu và Cao Văn Hùng, 2011. Đặc điểm sinh học và tập tính tụ đang trong vùng chiếu sáng của một số loài cá nổi nhỏ $\mathrm{xa}$ bờ biển Nam Trung Bộ. Tuyển tập Nghiên cứu nghề cá biển, tập VI. Viện Nghiên cứu Hải sản.

3. Kolding \& Skaalevik, 2010. Version 2.4. A database Package. Norway University of Bergen. 
Nguyễn Văn Hải

\title{
EFFECT OF LIGHT COLORS TO EXPLOIT FLY SQUID (STHENOTEUTHIS OUALANIENSIS LESSON, 1830) WITH STICK-HELD FALLING NET
}

\section{Nguyen Van Hai}

Research Institute for Marine Fisheries-Ministry of Agriculture and Rural Development

\begin{abstract}
In 2011, two offshore-survey trips was conducted in Central part using underwater lights of 170 hauls of squid, in which 3 kinds of color are yellow - green - white used. On average, each night 7 hauls was performed in order to ensure that each must be made at least 30 hauls with each haul takes 1 hour. The results indicate that the highest productivity in white and lowest in yellow, there is a significant difference between those lights, in contrast, the others lights showed insignificant difference at the $P<0.05$ level. There is no significant difference on average length of exploited squids among lights $(P<0.05)$.
\end{abstract}

Keywords: Fly squid, underwater lights, color light, squid hauls. 